Katarina Mårtensson, LUND UNIVERSITY, katarina.martensson@ahu.lu.se

NancyChick, ROLLINS COLLEGE,nchick@rollins.edu

\title{
Editors' Introduction TLI's Trajectory of Tradition and Change
}

Teaching \& Learning Inquiry (TLI) is changing. It's also staying the same.

Most noticeable are some immediately visible changes. The journal's transition to the newest version of Open Journal Systems (OJS) - the open-source online publishing system from the Public Knowledge Project-is now complete. Readers will notice that the appearance and navigability have been refreshed, and reviewers and authors will see some changes in their respective processes.

$T L I$ is also staying the same. A behind-the-scenes tradition is a defining feature of the journal, even though it's invisible to most of its readers. TLI is of course the journal of the International Society for the Scholarship of Teaching and Learning (ISSOTL), a relationship that calls for some intentional efforts. In addition to being the premiere journal in SoTL, TLI aspires to be the journal that meets its practitioners where they are. Before the publication of its first issue in 2013, TLI's founding coeditors - in conversation initially with ISSOTL's Board of Directors and then its Editorial Boardcommitted to an ethos of development: submitters would receive thoughtful, constructive, developmental feedback, regardless of the decision Accept with revisions, Revise and resubmit with no publication guaranteed, or Reject. Because SoTL is a secondary discipline for many of its practitioners, writing about it is typically an unfamiliar and, to some, even awkward experience. We know there's a difference between the write-up and the ideas, between the report of the SoTL project and the project itself. More often than not, we see submissions with potential to inform, provoke, and even transform in productive ways, but the written document hasn't yet fully captured that potential. As ISSOTL's journal, TLI should not simply be the journal for elite writers who are already skilled at expressing themselves in formal, written English for an international readership with radically diverse backgrounds, contexts and interests. This approach would miss too many important opportunities - the opportunities for reviewers to offer mentorship, for practitioners to learn to write for each other broadly, for the journal to contribute to the expansion and diversification of the field, and for SoTL to be both sustainable, inclusive, and evolving.

Still, TLI changes. Many readers already know of the personnel shift with the retirement of Gary Poole (one of its founding co-editors) and formation of a new editorial team, with continuing founding co-editor Nancy Chick. This moment was a good time to think about the journal and its future. Well before his retirement, Poole and Chick worked with ISSOTL's Publications Advisory Committee, led by Pat Hutchings, to dream of and implement an ideal editorial model for the journal. With the publication of issue 7.2, the result is now in place. As of January 2019, the three associate editors are shepherding most submissions through the review and production process, as well as developing the journal's peer review pool and processes, its international outreach, and its digital publications. As of July 1, Katarina Mårtensson joins Nancy Chick as co-editors who will remain engaged in the review and production 
processes but also — thanks to the associate editors — will have more time for strategic work that will keep TLI at the forefront of SoTL. How?

The editorial team will be reaching out more intentionally to do the following:

- invite and encourage submissions from thus far under-represented regions, disciplines, methods, and topics,

- continue to grow and support our reviewers, as they are the most important of the journal's "personnel,"

- broaden the genres represented in the journal, particularly calling for submissions that go beyond the text-based PDF,

- increase contributions to TLI Reviews that focus on the relevance and potential applications of conferences, books, external articles, and other resources relevant to readers, and

- call for submissions to proactively contribute to significant conversations and fill important gaps in the field.

You will be hearing more from us, and we hope to be hearing from more of you.

Katarina Mårtensson is senior lecturer in Higher Education Development at Lund University (Sweden).

Nancy Chick is director of the Endeavor Foundation Center for Faculty Development at Rollins College in Winter Park, Florida (USA).

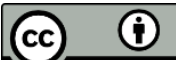

Copyright for the content of articles published in Teaching \& Learning Inquiry resides with the authors, and copyright for the publication layout resides with the journal. These copyright holders have agreed that this article should be available on open access under a Creative Commons Attribution License 4.0 International (https://creativecommons.org/licenses/by/4.0). The only constraint on reproduction and distribution, and the only role for copyright in this domain, should be to give authors control over the integrity of their work and the right to be properly acknowledged and cited, and to cite Teaching \& Learning Inquiry as the original place of publication. Readers are free to share these materials-as long as appropriate credit is given, a link to the license is provided, and any changes are indicated. 